\title{
Criteria and potential predictors of severity in patients with COVID-19
}

Niveen E. Zayed*, Ahmad Abbas and Samah Mohamad Lutfy

\begin{abstract}
Background: The challenge in treating severe COVID-19 in the absence of targeted medication is enforcing physicians to search carefully for clinical predictors of severity.

Aim: To define the profile of patients at risk of severe COVID-19 and to assess for certain predictors.

Methods: Confirmed COVID-19 cases were classified into the following: group A: mild/moderate cases and group B: severe/critical cases according to the selected criteria. History, radiological assessment, complete blood count, lactate dehydrogenase (LDH), myocardial enzymes, serum ferritin, and D dimer were assessed. Patients were followed for the need of ICU and mechanical ventilation. Duration till conversion, length of stay, and mortality were recorded.

Results: A total of 202 patients were analyzed. Group B had higher age ( $53.2 \pm 12.6$ vs $40.3 \pm 10.3, P<0.001)$, more prevalence of DM (60.61\% vs $16.57 \% P<0.001)$, hypertension $(51.52 \%$ vs $20.12 \%, P<0.001)$, ischemic heart $(27.27 \%$ vs $3.55 \%, P<0.001)$, bronchial asthma (36.36\% vs $3.55 \%, P<0.001)$, COPD $(9.09 \%$ vs $1.18 \%, P=0.03)$, higher mean platelet volume (MPV) (12.76 \pm 7.13 vs $10.51 \pm 7.78$ (fL), $P<0.001)$, higher serum ferritin (954 \pm 138 vs $447 \pm 166 \mathrm{ng} /$ $\mathrm{ml}, P<0.001)$, higher LDH (604 \pm 220 vs $384 \pm 183 \mathrm{U} / \mathrm{L}, P$-value $<0.001)$, higher creatine phosphokinase $(24.27 \pm 5.82$ vs $16.4 \pm 4.87 \mathrm{IU} / \mathrm{L}, P<0.001$ ), and higher mortality (30.3\% vs $0.6 \%, P<0.001)$. Multivariate regression of predictors of severity identified three predictors; age, MPV, serum ferritin, and IHD.
\end{abstract}

Conclusions: The current study places of interest the characteristic host-related features of severe COVID-19 and draws attention to potential predictors.

Keywords: COVID-19, Ferritin, ICU, Mean platelet volume

\section{Introduction}

An outbreak of pneumonia of unidentified etiology was discovered in Wuhan city, China, in December 2019; the scientist succeeded in early January 2020 to isolate a novel virus which seems to belong to the genus Betacoronavirus, Coronaviridae family. They gave them a name, SARS-CoV-2 [1-4]. Later on, WHO gave the disease its unique name, COVID-19, and announced it as a pandemic by 11 February 2020 [5, 6].

The most common presentation of COVID-19 pneumonia is fever, dry cough, and dyspnea, which may be

\footnotetext{
*Correspondence: niveenzayed@yahoo.com

Chest Department, Faculty of Medicine, Zagazig University,

Zagazig 44519, Egypt
}

associated with fatigue and myalgia. Most of the cases had a mild to moderate course of disease and recovered after good medical intervention. A small number of patients may develop severe pneumonia, $15-32 \%$, with acute respiratory distress syndrome (ARDS) and multiple organ failure, or even death [5,7-10].

The fatality rate ranged from 1 to $15 \%$ [11]. The challenge in treating severe and critically ill cases with COVID-19 especially with the absence of specific and targeted medication enforcing the physician to search carefully for clinical characteristics of severe COVID19 pneumonia and subsequent predictors in order to start the optimum standard of care as early as possible. Growing reports highlighted old age, cardiovascular comorbidity, and diabetes mellitus as predictors of 
severe course of disease [12]. Others identified several biomarkers to help in predicting severe and fatal coronavirus disease 2019 (COVID-19) such as serum ferritin, D-dimer, and cardiac enzymes [13]. The aim of this work is to define the profile of patients at risk of severe COVID-19 and to assess for certain predictors of severity.

\section{Patients and methods}

This is an observational cross-sectional study including 202 patients diagnosed to have COVID-19. The study was conducted at Zagazig University isolation hospitals from the period of March 2020 to June 2021. The study was approved by Zagazig University Ethics Committee (number 9229). Written informed consent was obtained from all participants.

\section{Inclusion criteria}

The study includes laboratory-confirmed COVID-19 patients (confirmed by real-time polymerase chain reaction) admitted l during the period of the study.

The patients were classified into two groups: group A included mild/moderate cases and group B included severe/critical cases according to the following criteria.

Severity of COVID-19 was graded as follows: (1) mild: mild clinical symptoms, no pneumonia on lung CT; (2) moderate: fever, cough, and lung CT with pneumonia; (3) severe: respiratory distress (respiratory rate $>30 / \mathrm{min}$, oxygen saturation $(\mathrm{O} 2 \mathrm{Sat}) \leq 93 \%$ at rest and/or ratio of arterial oxygen partial pressure to fractional inspired oxygen $\leq 300 \mathrm{mmHg}\left(\mathrm{PaO}_{2} / \mathrm{FIO}_{2}\right)$; and (4) critical: aforementioned criteria of respiratory failure receiving mechanical ventilation, shock, and/or organ failure other than lung and/or intensive care unit (ICU) hospitalization $[14,15]$.

All participants were subjected to full history taking including smoking history and comorbidity profile. Clinical symptoms including fever, cough, dyspnea, myalgia, hemoptysis, sore throat, diarrhea, loss of smell, and anorexia were recorded. Radiological assessment by initial chest $\mathrm{x}$-ray then $\mathrm{CT}$ chest as possible and appropriate. Routine laboratory investigations: complete blood count $(\mathrm{CBC})$, coagulation profile, serum biochemical tests (including renal and liver function, and electrolytes), laboratory investigation to assess the severity of COVID19: lactate dehydrogenase (LDH), myocardial enzymes (CPK-MB), serum ferritin, D dimer, and arterial blood gas analysis. Patients were followed up for the need for ICU and mechanical ventilation (MV), duration till conversion, total length of stay, and final outcome whether survived or died were recorded.

\section{Statistical methods}

The statistical analysis was done using Minitab 17.1.0.0 for Windows (Minitab Inc., 2013, Pennsylvania, USA). The data normality was examined using the ShapiroWilk test, the continuous data represented as mean and standard deviation (SD), and categorical data as number and percentage (\%). Comparison between two means was done using independent $t$ test, while chi-square test compared the frequency of two groups or more. Logistic regression analysis test with backward elimination methods was used to predict the factors associated with severity. The accuracy of MPV and ferritin were assessed using receiver operating curve analysis; assuming that the area under the ROC curve of 0.9 for this study was significant with margin of type I error 0.05 and type II error 0.1 , the sample size calculated with a minimum total number of 70 and the minimum number of cases with severe COVID-19 was 35 using SigmaPlot software 12.5.0.38 for Windows (SigmaPlot, Systat Software Inc. UK, 2011). All tests were two sided, $P$ considered significant if $<0.05$.

\section{Results}

This study analyzed 202 patients proved to have COVID19 by real time PCR, they were classified into two groups, group A with mild/moderate COVID-19 and group B with severe/critical COVID-19 (Fig. 1) according to the aforementioned criteria. Table 1 demonstrates the demographic data of both groups where group B had higher age $(53.2 \pm 12.6$ vs $40.3 \pm 10.3, P<0.001)$, more prevalence of comorbidity profile, DM $(60.61 \%$ vs $16.57 \% P<0.001)$, hypertension $(51.52 \%$ vs $20.12 \%, P<$ $0.001)$, ischemic heart disease (IHD) $(27.27 \%$ vs $3.55 \%, P$ $<0.001$ ), bronchial asthma (36.36\% vs $3.55 \%, P<0.001$ ), COPD $(9.09 \%$ vs $1.18 \%, P=0.03)$, and hyperlipidemia (12.12\% vs $2.37 \%, P=0.01)$.

The clinical characteristics of the studied COVID-19 patients are shown in Table 2, which revealed that group $B$ had longer duration of symptoms before admission ( $5.55 \pm 2.15$ days vs $3.89 \pm 1.1$ days, $P<0.001)$. Regarding the presenting symptoms, group $B$ had more prevalence of dyspnea $(81.82 \%$ vs $37.28 \%, P<0.001)$, cough $(100 \%$ vs $83.43 \%, P=0.012)$, myalgia ( $66.67 \%$ vs $46.15 \%, P=0.03)$, hemoptysis $(24.24 \%$ vs $0 \%, P<0.001)$, diarrhea $(72.73 \%$ vs $43.2 \%, P=0.002)$, loss of smell $(48.5 \%$ vs $29.59 \%, P=$ $0.034)$, anorexia (39.4\% vs $21.3 \%, P=0.27$ ).

Regarding the radiological presentation, abnormalities were bilateral in all cases of group B vs $71.6 \%$ in group A with $P$-value $<0.001$, more reticular infiltrates $36.4 \%$ in group B vs $10.6 \%$ in group A with $P$-value 0.02 and more ground-glass opacities (GGO) $72.73 \%$ in group $B$ vs $19.53 \%$ in group A with $P$-value $<0.001$ as shown in Table 3. 


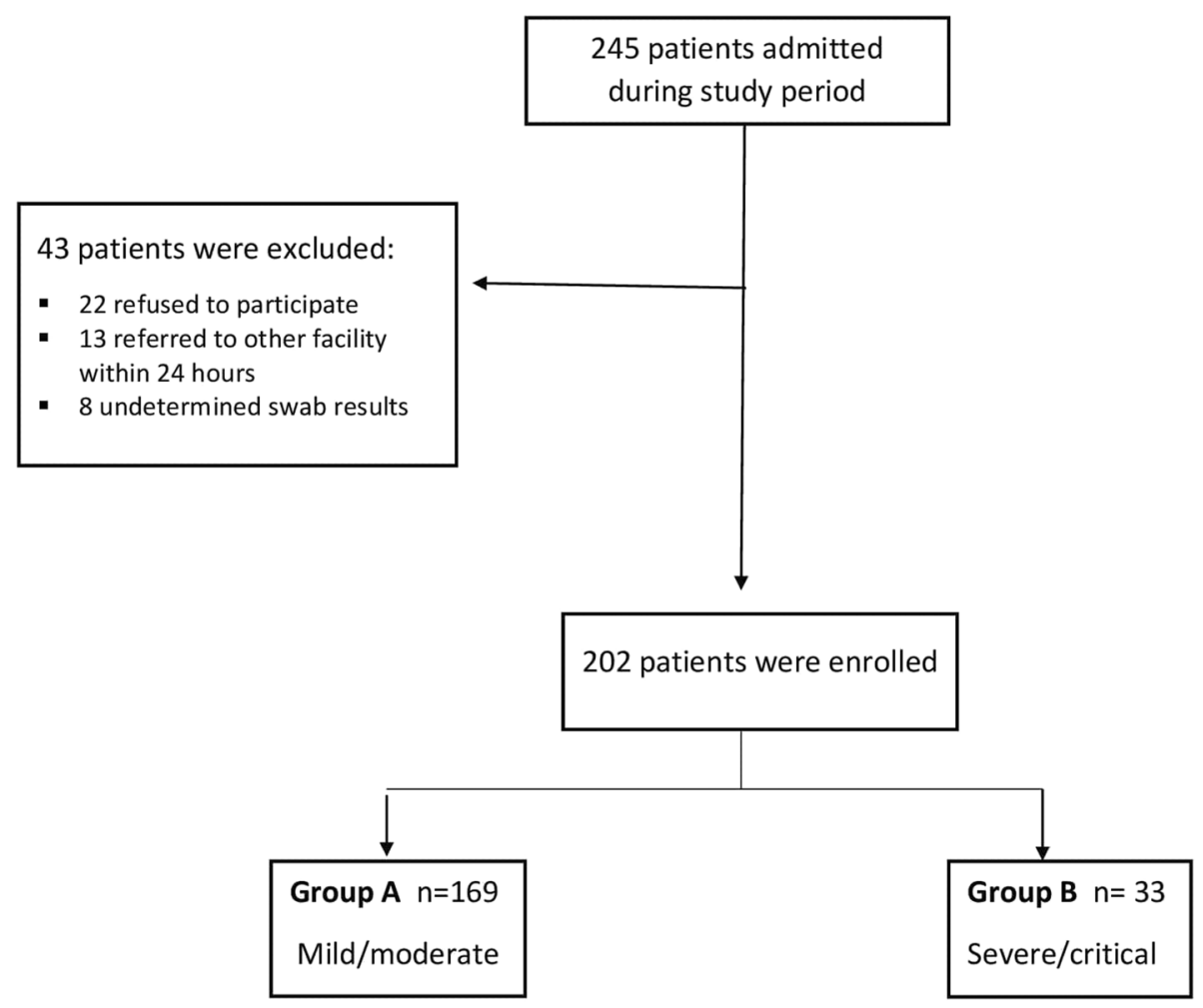

Fig. 1 Flow chart of the studied population

Laboratory assessment of patients on admission is shown in Table 4, which revealed the followings in group B compared to group A; more lymphopenia (16.18\% $\pm 7.13 \%$ for group B vs $42.1 \% \pm 7.78 \%$ for group A $P<$ $0.001)$, higher MPV ( $12.76 \pm 7.13$ (fL) vs $10.51 \pm 7.78$ (fL), $P<0.001)$, higher ESR $(60.4 \pm 17.7(\mathrm{~mm} / \mathrm{h})$ vs 39

Table 1 Demographic data of the studied COVID-19 patients

\begin{tabular}{llll}
\hline Variables & $\begin{array}{l}\text { Mild \& moderate } \\
(\boldsymbol{n}=\mathbf{1 6 9})\end{array}$ & $\begin{array}{l}\text { Severe \& critical } \\
(\boldsymbol{n}=\mathbf{3 3})\end{array}$ & $\boldsymbol{P}$-value \\
\hline Age & $40.3 \pm 10.3$ & $53.2 \pm 12.6$ & $<0.001^{*}$ \\
Sex (male) & $133(78.7 \%)$ & $29(87.9 \%)$ & $0.23^{\ddagger}$ \\
Smoking & $48(28.4 \%)$ & $12(36.4 \%)$ & $0.36^{\ddagger}$ \\
Comorbidities & & & \\
DM & $28(16.6 \%)$ & $20(60.6 \%)$ & $<0.001^{\ddagger}$ \\
Hypertension & $34(20.1)$ & $17(51.5 \%)$ & $<0.001^{\ddagger}$ \\
IHD & $6(3.6 \%)$ & $9(27.3 \%)$ & $<0.001^{\ddagger}$ \\
Bronchial asthma & $6(3.6 \%)$ & $12(36.4 \%)$ & $<0.001^{\ddagger}$ \\
COPD & $2(1.2 \%)$ & $3(9.1 \%)$ & $0.03^{\ddagger}$ \\
Hyperlipidemia & $4(2.4 \%)$ & $4(12.1 \%)$ & $0.01^{\ddagger}$ \\
Hypothyroidism & $2(1.2 \%)$ & $0(0 \%)$ & $1^{\ddagger}$
\end{tabular}

Continuous data represented as mean and SD, and categorical data represented as number and percentage (\%). ${ }^{*}$ Independent samples Student's $t$-test; ${ }^{*} \mathrm{chi}$ square test; $P<0.05$ is significant; $D M$, diabetes mellitus; $I H D$, ischemic heart disease; $C O P D$, chronic obstructive pulmonary disease $\pm 19.6(\mathrm{~mm} / \mathrm{h}), P<0.001)$, higher CRP $(119.5 \pm 45.6$ $\mathrm{mg} / \mathrm{L}$ vs $59.6 \pm 39.5 \mathrm{mg} / \mathrm{L}, P<0.001)$, higher serum ferritin $(954 \pm 138 \mathrm{ng} / \mathrm{ml}$ vs $447 \pm 166 \mathrm{ng} / \mathrm{ml}, P<0.001)$, more positive D-dimer $(75.8 \%$ vs $20.7 \%,<0.001)$, higher $\mathrm{LDH}(604 \pm 220 \mathrm{U} / \mathrm{L}$ vs $384 \pm 183 \mathrm{U} / \mathrm{L}, P$-value $<0.001)$, higher AST $(69 \pm 37 \mathrm{U} / \mathrm{L}$ vs $51.7 \pm 25.4 \mathrm{U} / \mathrm{L}, P=0.01)$,

Table 2 Clinical characteristics of the studied COVID-19 patients

\begin{tabular}{llll}
\hline Variables & $\begin{array}{l}\text { Mild \& moderate } \\
(\boldsymbol{n}=\mathbf{1 6 9 )}\end{array}$ & $\begin{array}{l}\text { Severe \& } \\
\text { critical }(\boldsymbol{n}=\mathbf{3 3})\end{array}$ & $\boldsymbol{P}$-value \\
\hline $\begin{array}{l}\text { Duration of symptoms } \\
\text { before admission }\end{array}$ & $3.9 \pm 1.1$ & $5.6 \pm 2.2$ & $<0.001^{*}$ \\
Fever & $151(89.4 \%)$ & $30(90.9 \%)$ & $0.79^{\ddagger}$ \\
Cough & $141(83.4 \%)$ & $33(100 \%)$ & $0.012^{\ddagger}$ \\
Expectoration & $16(9.5 \%)$ & $0(0 \%)$ & $0.07^{\ddagger}$ \\
Dyspnea & $63(37.3 \%)$ & $27(81.8 \%)$ & $<0.001^{\ddagger}$ \\
Myalgia & $78(46.2 \%)$ & $22(66.7 \%)$ & $0.03^{\ddagger}$ \\
Sore throat & $59(34.9 \%)$ & $9(27.3 \%)$ & $0.39^{\ddagger}$ \\
Hemoptysis & $0(0 \%)$ & $8(24.2 \%)$ & $<0.001^{\ddagger}$ \\
Diarrhea & $37(43.2 \%)$ & $24(72.7 \%)$ & $0.002^{\ddagger}$ \\
Loss of smell & $50(29.6 \%)$ & $16(48.5 \%)$ & $0.034^{\ddagger}$ \\
Anorexia & $36(21.3 \%)$ & $13(39.4 \%)$ & $0.027^{\ddagger}$ \\
\hline
\end{tabular}

Continuous data represented as mean and SD, and categorical data represented as number and percentage (\%).*Independent samples Student's $t$-test; ${ }^{\ddagger}$ chisquare test; $P<0.05$ is significant 
Table 3 Chest x-ray and CT abnormalities of studied COVID-19 patients

\begin{tabular}{|c|c|c|c|}
\hline Variables & $\begin{array}{l}\text { Mild \& moderate } \\
(n=169)\end{array}$ & $\begin{array}{l}\text { Severe \& critical } \\
(n=33)\end{array}$ & $P$-value \\
\hline $\begin{array}{l}\text { Radiological infil- } \\
\text { trates (yes) }\end{array}$ & $121(71.6 \%)$ & $33(100 \%)$ & $<0.001^{\ddagger}$ \\
\hline Bilateral & 77 (45.6\%) & $33(100 \%)$ & $<0.001^{\ddagger}$ \\
\hline Nodular & $10(5.9 \%)$ & $2(6.1 \%)$ & $0.76^{\ddagger}$ \\
\hline Reticular & $18(10.6 \%)$ & $12(36.4 \%)$ & $0.02^{\ddagger}$ \\
\hline GGO & 32 (19.5\%) & $24(72.7 \%)$ & $<0.001^{\ddagger}$ \\
\hline
\end{tabular}

Categorical data represented as number and percentage (\%). ${ }^{\ddagger}$ chi-square test; $P<0.05$ is significant; $G G O$, ground-glass opacity

Table 4 Laboratory assessment of the studied COVID-19 patients on admission

\begin{tabular}{|c|c|c|c|}
\hline Variables & $\begin{array}{l}\text { Mild/moderate } \\
(n=169)\end{array}$ & $\begin{array}{l}\text { Severe/critical } \\
(n=33)\end{array}$ & $P$-value \\
\hline \multicolumn{4}{|c|}{ Laboratory investigation } \\
\hline TLC & $5.97 \pm 1.92$ & $6.7 \pm 3.4$ & $0.19^{*}$ \\
\hline Platelet & $201.3 \pm 61.9$ & $187.5 \pm 70.2$ & $0.23^{*}$ \\
\hline $\mathrm{HgB}$ & $15.3 \pm 1.6$ & $14.2 \pm 2.6$ & $0.02^{*}$ \\
\hline \%Lymph & $42.1 \pm 7.8$ & $16.2 \pm 7.1$ & $<0.001^{*}$ \\
\hline MPV & $10.5 \pm 1.8$ & $12.8 \pm 7.1$ & $<0.001^{*}$ \\
\hline ESR & $39 \pm 19.6$ & $60.4 \pm 17.7$ & $<0.001^{*}$ \\
\hline CRP & $59.6 \pm 39.5$ & $119.5 \pm 45.6$ & $<0.001^{*}$ \\
\hline Ferritin & $447 \pm 166$ & $954 \pm 138$ & $<0.001^{*}$ \\
\hline Positive D-dimer & $35(20.7 \%)$ & $25(75.8 \%)$ & $<0.001^{\ddagger}$ \\
\hline LDH & $384 \pm 183$ & $604 \pm 220$ & $<0.001^{*}$ \\
\hline AST & $51.7 \pm 25.4$ & $69 \pm 37$ & $0.01^{*}$ \\
\hline ALT & $48.2 \pm 26.5$ & $59.5 \pm 17.7$ & $0.01^{*}$ \\
\hline Creatinine & $0.8 \pm 0.2$ & $1.3 \pm 0.7$ & $0.01^{*}$ \\
\hline CPK-MB & $16.4 \pm 4.9$ & $24.3 \pm 5.8$ & $<0.001^{*}$ \\
\hline \multicolumn{4}{|l|}{ ABG } \\
\hline $\mathrm{PH}$ & $7.4 \pm 0.3$ & $7.4 \pm 0.6$ & 0.06 \\
\hline $\mathrm{PCO}_{2}$ & $37.4 \pm 3.6$ & $32 \pm 3.9$ & $<0.001^{*}$ \\
\hline $\mathrm{PO}_{2}$ & $70.8 \pm 9.3$ & $49.6 \pm 2.6$ & $<0.001^{*}$ \\
\hline $\mathrm{HCO}_{3}$ & $20.9 \pm 1.97$ & $19.6 \pm 2.8$ & $0.03^{*}$ \\
\hline $\mathrm{Na}$ & $131.7 \pm 4.5$ & $129.7 \pm 4.7$ & $0.03^{*}$ \\
\hline K & $3.5 \pm 0.4$ & $3.2 \pm 0.6$ & $0.02^{*}$ \\
\hline
\end{tabular}

Continuous data represented as mean and SD, and categorical data represented as number and percentage (\%).*Independent samples Student's $t$-test; ${ }^{\ddagger}$ chi-square test; $P<0.05$ is significant; $T L C$, total leucocyte count (cell/ $\mu \mathrm{L})^{3} ; P L T$, platelet count (cell/ $\mu \mathrm{L}$ ) ${ }^{3} ; \mathrm{HgB}$, hemoglobin (gm/dL); \%Lymph (cell/ $\mu \mathrm{L})^{3} ; M P V$, mean platelet volume (fL); $E S R$, erythrocyte sedimentation rate $(\mathrm{mm} / \mathrm{h}) ; C R P, C$-reactive protein $(\mathrm{mg} / \mathrm{L}) ;$ ferritin $(\mathrm{ng} / \mathrm{ml}) ; \mathrm{D}$-dimer, $(\mathrm{mg} / \mathrm{L}) ; \mathrm{LDH}$, lactate dehydrogenase $(\mathrm{U} / \mathrm{L}) ; A S T$, aspartate transaminase $(\mathrm{U} / \mathrm{L}) ; A L T$, alanine aminotransferase $(\mathrm{U} / \mathrm{L})$; creatinine $(\mathrm{mg} / \mathrm{dL}) ; C P K-M B$, creatine kinase myocardial band (IU/L); $P \mathrm{CO}_{2}$, partial pressure of arterial carbon dioxide $(\mathrm{mm} \mathrm{HG}) ; P \mathrm{O}_{2}$, partial pressure of arterial oxygen ( $\mathrm{mm} \mathrm{HG}$ ); $\mathrm{Na}$, sodium (mEq/L); $K$, potassium $(\mathrm{mmol} / \mathrm{L})$
Table 5 Outcome of the studied COVID-19 patients

\begin{tabular}{llll}
\hline Variables & $\begin{array}{l}\text { Mild/moderate } \\
(\boldsymbol{n}=\mathbf{1 6 9 )}\end{array}$ & $\begin{array}{l}\text { Severe/critical } \\
(\boldsymbol{n}=\mathbf{3 3})\end{array}$ & $\boldsymbol{P}$-value \\
\hline $\begin{array}{l}\text { Duration till con- } \\
\text { version }\end{array}$ & $7.88 \pm 2.5$ & $9.4 \pm 2.6$ & $0.03^{*}$ \\
LOS & $7.6 \pm 1.7$ & $10.7 \pm 3.1$ & $0.001^{*}$ \\
Need ICU & $51(30.2 \%)$ & $33(100 \%)$ & $<0.001^{\ddagger}$ \\
Need MV & $4(2.4 \%)$ & $29(87.9 \%)$ & $<0.001^{\ddagger}$ \\
Death & $1(0.6 \%)$ & $10(33.3 \%)$ & $<0.001^{\ddagger}$
\end{tabular}

Continuous data represented as mean and SD, and categorical data represented as number and percentage (\%). ${ }^{*}$ Independent samples Student's $t$-test; ${ }^{\ddagger}$ chisquare test; $P<0.05$ is significant; $L O S$, length of stay

Table 6 Predictors of severity of COVID-19 patients using regression analysis

\begin{tabular}{llll}
\hline Variables & OR & $\mathbf{9 5 \%} \mathbf{C l}$ & $\boldsymbol{P}$-value \\
\hline Age & 1.5 & $(1.21-1.93)$ & 0.044 \\
MPV & 6.7 & $(1.32-3.68)$ & 0.004 \\
Ferritin & 2.04 & $(1.2-3.5)$ & 0.016 \\
IHD & 3.1 & $(1.3-4.9)$ & 0.003
\end{tabular}

Pearson, $X^{2}=9.32, P=0.316$

higher ALT $(59.5 \pm 17.7 \mathrm{U} / \mathrm{L}$ vs $48.2 \pm 26.5 \mathrm{U} / \mathrm{L}, P=$ $0.01)$, higher creatinine $(1.25 \pm 0.65 \mathrm{mg} / \mathrm{dL}$ vs $0.83 \pm$ $0.2 \mathrm{mg} / \mathrm{dL}, P=0.01)$, and higher CPK-MB $(24.27 \pm 5.82$ $\mathrm{IU} / \mathrm{L}$ vs $16.4 \pm 4.87 \mathrm{IU} / \mathrm{L}, P<0.001)$.

Group B also had more hypoxemia than group A (49.58 $\pm 2.59 \mathrm{mmHg}$ vs $70.77 \pm 9.31 \mathrm{mmHg}$ respectively, $P<$ $0.001)$ in ambient air, lower $\mathrm{PCO}_{2}(32.01 \pm 3.94 \mathrm{mmHg}$ vs $37.41 \pm 3.56 \mathrm{mmHg}$ respectively, $P<0.001$ ), lower Na $(129.7 \pm 4.7 \mathrm{mEq} / \mathrm{L}$ vs $131.72 \pm 4.5 \mathrm{mEq} / \mathrm{L}$, respectively, $P=0.03)$ and lower $\mathrm{K}(3.19 \pm 0.6 \mathrm{mmol} / \mathrm{L}$ vs $3.46 \pm 0.43$ $\mathrm{mmol} / \mathrm{L}$ respectively, $P=0.02$ ).

Regarding the outcome of both groups; group B had longer duration till conversion $(9.44 \pm 2.6$ vs $7.88 \pm 2.5$ days, $P=0.03)$, longer length of hospital stays (10.7 \pm 3.13 vs $7.6 \pm 1.65$ days, $P=0.001)$, more ICU admission (100\% vs $30.18 \%, P<0.001)$, more need of MV $(87.9 \%$ vs $2.37 \%, P<0.001)$ and higher mortality rate $(33.3 \%$ vs $0.6 \%, P<0.001)$ as shown in Table 5.

Multivariate regression of potential predictors of COVID-19 severity is shown in Table 6 and revealed the following predictors: age $(\mathrm{OR}=1.542, \mathrm{CI}=1.21-1.93)$, $\mathrm{MPV}(\mathrm{OR}=6.67, \mathrm{CI}=1.32-3.68)$, serum ferritin $(\mathrm{OR}$ $=2.04, \mathrm{CI}=1.19-3.47)$, and IHD with $(\mathrm{OR}=3.1, \mathrm{CI}=$ $1.25-4.94)$.

Table 7 and Figs. 2 and 3 report the overall results of the ROC analysis regarding MPV and serum ferritin as predictors of COVID-19 severity. A cutoff of ferritin > $548.5 \mathrm{ng} / \mathrm{ml}$ yielded $91 \%$ sensitivity, $71 \%$ specificity, $43 \%$ positive predictive value (PPV), 97\% negative predictive 
Table 7 Validity of ferritin and MPV in predicting COVID-19 severity

\begin{tabular}{lllllll}
\hline Variable cutoff & Sensitivity (95\%Cl) & Specificity (95\%Cl) & PPV (95\%Cl) & NPV (95\%Cl) & AUC (95\%Cl) & P-value \\
\hline Ferritin > 548.5 ng/ml & $91 \%(75.6-98.1)$ & $74 \%(66.9-80)$ & $43 \%(19.7-51.5)$ & $97 \%(84.8-99.1)$ & $0.87(0.79-0.94)$ & $<0.001$ \\
MPV > 9.5 fL & $96 \%(84.2-99)$ & $63 \%(29.2-44.3)$ & $25 \%(16.3-35.8)$ & $98 \%(85.3-99.5)$ & $0.83(0.75-0.9)$ & $<0.001$ \\
\hline
\end{tabular}

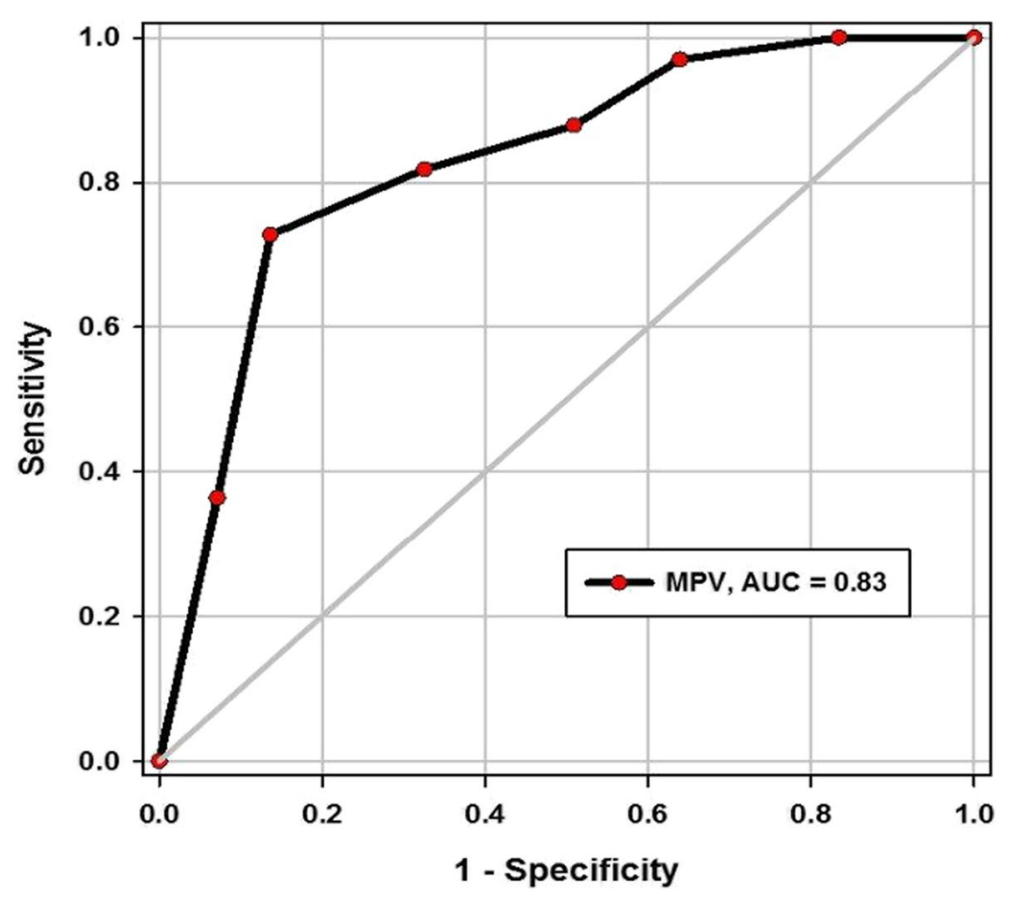

Fig. 2 Receiver operating characteristic (ROC) curve for MPV in predicting severity of COVID-19

value (NPV) (AUC, 0.87). A cutoff of MPV > 9.5 (fL) yielded $96 \%$ sensitivity, $63 \%$ specificity, $25 \%$ positive predictive value (PPV), 98\% negative predictive value (NPV) (AUC, 0.83).

\section{Discussion}

The aspects of COVID-19 disease are widely ranging from asymptomatic condition up to multi-organ dysfunction. The clinical presentation cannot be discriminated from other respiratory diseases; hence, they share the common features such as fever, headache, fatigue, sore throat, cough, and dyspnea [7].

As mentioned in published reports, about 20 to $30 \%$ of patients progress to have pneumonia that need hospitalization and could be deteriorating to acute respiratory distress (ARDS) and death [16].

The host-related factors such as older age and presence of comorbidities play a significant role in determining the course of disease [17], which support the current data, as the elderly patients with DM, hypertension (HTN), ischemic heart disease (IHD), and chronic respiratory disease significantly suffered from severe disease. In the same line, Du et al. [18] found age above 65 years with cardiovascular and cerebrovascular comorbidities associated with severe COVID-19 diseases. Moreover, He et al. [19] added that patients with chronic kidney disease had severe a COVID-19 course.

A recent meta-analysis summarizes the linked hostrelated risk factors and concluded that severe COVID19 patients are more likely to be older with associated different cardiovascular and respiratory comorbidities and explained that by weak immune function [20]. However, in other studies, the risk factors were different and included male sex, smoking habits, and obesity [21, 22].

Considering the radiological workup, the present work highlights in brief the role of CT chest in characterizing severe COVID-19 patients; hence, they significantly presented with a bilateral lesion, mostly GGO and reticulation. Many studies support our finding; thus, CT plays a significant role in diagnosing the pulmonary changes associated with SARS-CoV-2 infection with higher sensitivity action [7]. 


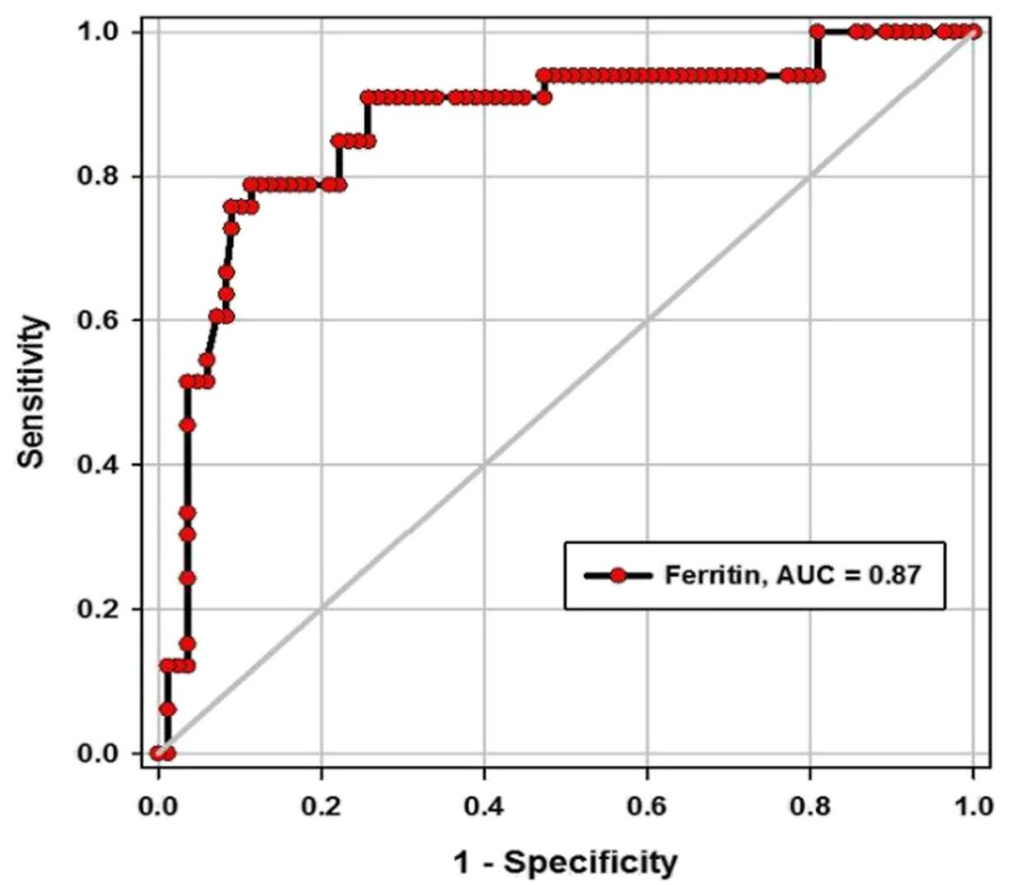

Fig. 3 Receiver operating characteristic (ROC) curve for serum ferritin in predicting severity of COVID-19

Like other respiratory viruses, SARS-CoV-2 infection implies different hematological changes, which help in the evaluation and monitoring of disease severity. The commonest changes in the hematopoietic system are lymphocytopenia, neutrophilia, thrombocytosis, or thrombocytopenia; therefore, during the course of the disease, the total leukocyte count may show normal value, decrease, or increase [23]. The present data recorded that the relative lymphocyte count was significantly decreased in the severe group rather than the mild and moderate ones, while total leucocytic count (TLC) and platelet (PLT) count showed insignificant differences that came in agreement with other reports; thus, the inflammatory cells were consumed during the immune response $[24,25]$. On the other hand, a contrary study recorded elevated TLC and PLT count in severe COVID-19 [19].

Taking into consideration other laboratory findings, we reported elevation in ESR, CRP, LDH, AST, ALT, CPK-MB, D-dimer, and creatinine levels in severe COVID-19 patients, which came in accordance with previous studies. In consequence, the hypercoagulable state is implicated in the formation of tiny thrombi in different organs, which later on promote a bad prognosis. Accordingly, the tests of coagulation profile help in assessing the critical patients as well as guiding the treatment intervention [26-28].
Considering the role of ferritin and its role during immune response toward infection, the idea focused on the mandatory function of iron in viral replication inside the cells; moreover, iron increases the sensitivity of $\mathrm{T}$ lymphocytes toward the chemical mediators, which finally helps in the regulation of ferritin expression. Ferritin plays an important immune modulator action by its heavy and light chains (HFC and LFC), through binding to iron molecules; consequently, the biological available form of iron protects the cellular proteins, lipids, and DNA from the toxicity of heavy metals. As a response to the inflammatory process toward viral infection including SARS-CoV-2, a significant elevation of serum ferritin level was noticed, as the pro-inflammatory cytokines particularly IL-6 stimulate the production of hepcidin, which upregulates the level of ferritin [29-32].

Our data showed significant elevation of the ferritin level in severe COVID-19 patients, and its sensitivity in predicting disease severity reached $91 \%$ at cutoff level > $548.5 \mathrm{ng} / \mathrm{mL}$. In addition, it could be used as independent predictors of severe COVID-19, and so, the likelihood of severity increased twofold more with every unit increase in the ferritin level; $\mathrm{OR}=2.04, P=0.016$. Using ferritin as a biomarker for severe SARS-CoV-2 infection was discussed by a recent publication, especially in Asian areas with a recommendation of empowering the study by more observations, as the finding was not conclusive; 
hence, the level of ferritin was elevated in different types of infections and in all COVID-19 patients [33].

On the other hand, Velavan et al. and Mehta et al. considered ferritin a significant predictor of severe COVID-19 disease and mortality due to secondary hemophagocytic lymphohistiocytosis (sHLH) and cytokine storm syndrome. Another important index involved in evaluating inflammatory condition was MPV; it correlates with platelet activation and reflects prothrombotic conditions [34-36].

The role of platelets in inflammation and immune regulation is crucial; hence, the activated platelets in viral infection induced lung injury through different mechanisms; first, direct damage of respiratory tract by released inflammatory mediators; second, surface exposure of $\mathrm{E}$ and $\mathrm{P}$ selectin that attract other inflammatory cells causing inflammatory and immune responses. The MPV is an important platelet index that represents platelet activation and indirectly correlates with platelet count. The decrease of platelet count is associated with poor outcome even mortality as well as the increase of MPV [37-40].

In our study, the platelets count was lower in the severe group than in the mild and moderate ones but with insignificant differences; in spite of that, the MPV was significantly higher in the severe group than the mild/moderate one. Moreover, the performance of MPV in predicting severe COVID-19 disease was very good; hence, the AUC was $83 \%$. In addition, the sensitivity of MPV at cutoff point > $9.5 \mathrm{fL}$ was higher (96\%). Furthermore, MPV could be used as independent predictors for severe COVID-19, thus the likelihood of severity increased 7 -fold for every unit increase of MPV; OR $=6.67, P<0.001$.

The study conducted by $\mathrm{He}$ et al. [19] showed that platelet count was significantly lower in severe disease, and was considered a predictor for mortality, in disagreement with the present results; hence, the authors neglect the role of the MPV index. However, a limited study discussed the predictive role of MPV in severe COVID19 disease; a Turkish study examined the correlation between the MPV value in two age groups (above and below 65) [41]. The results suggested irrelevant correlation, and the author recommended a larger study for significant findings. Another retrospective study by Zhong et al. [42] inspected the role of mean platelet volume over platelet count in predicting severe COVID-19 pneumonia and concluded that the capability of that ratio was higher and could be considered independent risk factors.

The strength of the current study is the idea about MPV and ferritin and their predictive ability of severe COVID-19 disease. In spite of the study being a preliminary prospective observation from one medical center, it gave a brief highlight about different independent predictors of the severity of that novel virus.

The limitation was subjected around the lack of other more specific laboratory markers reflecting the inflammatory state and cytokine storm such as IL-1, 6, and 8, TNF $\alpha$, and CD4 and CD8 counts, but the introduction of common markers that can be easily available was our target. Consequently, further studies are recommended to emphasize the underlying disease pathogenesis.

In conclusion, the study highlights the related aspects of severe COVID-19 disease and draws attention to predictors of severity besides the easy use of available biomarkers such as ferritin and MPV to facilitate the initial detection of a bad prognosis.

\section{Acknowledgements \\ Not applicable}

\section{Authors' contributions}

ZN, AA, and LM all shared in the conception, design of the work, and acquisition, analysis, and interpretation of the data. The authors read and approved the final manuscript.

Funding

No financial support or sponsorship.

Availability of data and materials

The database used and analyzed during the current study are available from the corresponding author on reasonable request

\section{Declarations}

Ethics approval and consent to participate

The study was approved by the Ethics Committee of Saudi National Hospital. Written informed consent was obtained from all participants.

\section{Consent for publication}

Not applicable

Competing interests

The authors declare no competing interests.

Received: 15 October 2021 Accepted: 5 February 2022

Published online: 19 February 2022

\section{References}

1. Phelan AL, Katz R, Gostin LO (2020) The novel coronavirus originating in Wuhan, China: challenges for global health governance. JAMA 323(8):709-710

2. Singhal T (2020) A review of coronavirus disease-2019 (COVID-19). Indian J Pediatrics 13:1-6

3. Zhu N, Zhang D, Wang W, Li X, Yang B, Song J et al (2020) A novel coronavirus from patients with pneumonia in China, 2019. NEJM 382(8):727-733

4. Abbas A, Al-Otaibi T, Gheith OA, Nagib AM, Farid MM, Walaa M (2021) Sleep quality among healthcare workers during the COVID-19 pandemic and its impact on medical errors: Kuwait experience. Turkish Thoracic J 22(2):142

5. Lotfy SM, Abbas A, Shouman W (2021) Use of hydroxychloroquine in patients with COVID-19: a retrospective observational study. Turk Thorac J 22(1):62-66

6. Mahévas M, Tran VT, Roumier M, Chabrol A, Paule R, Guillaud C et al (2020) Clinical efficacy of hydroxychloroquine in patients with covid-19 
pneumonia who require oxygen: observational comparative study using routine care data. BMJ. 369:m1844

7. Li Q, Guan X, Wu P, Wang X, Zhou L, Tong Y et al (2020) Early transmission dynamics in Wuhan, China, of novel coronavirus-infected pneumonia. NEJM 26;382(13):1199-207.

8. Huang C, Wang Y, Li X, Ren L, Zhao J, Hu Y et al (2020) Clinical features of patients infected with 2019 novel coronavirus in Wuhan, China. Lancet 395(10223):497-506

9. Wu Z, McGoogan JM (2020) Characteristics of and important lessons from the coronavirus disease 2019 (COVID-19) outbreak in China: summary of a report of 72314 cases from the Chinese Center for Disease Control and Prevention. JAMA 323(13):1239-1242

10. AlOtaibi TM, Gheith OA, Abuelmagd MM, Adel M, Alqallaf AK, Elserwy NA et al (2021) Better outcome of COVID-19 positive kidney transplant recipients during the unremitting stage with optimized anticoagulation and immunosuppression. Clin Transpl 25:e14297

11. Chen N, Zhou M, Dong X, Qu J, Gong F, Han Y et al (2020) Epidemiological and clinical characteristics of 99 cases of 2019 novel coronavirus pneumonia in Wuhan, China: a descriptive study. Lancet. 395:507-513

12. Zhou F, Yu T, Du R, Fan G, Liu Y, Liu Z et al (2020) Clinical course and risk factors for mortality of adult inpatients with COVID-19 in Wuhan, China: a retrospective cohort study. Lancet. 395:1054-1062

13. Korean Society of Infectious Diseases and Korea Centers for Disease Control and Prevention (2020) Analysis on 54 mortality cases of coronavirus disease 2019 in the Republic of Korea from January 19 to March 10, 2020. J Korean Med Sci 35:e132

14. Egyptian Ministry of Health $(\mathrm{MOH})$ Guidelines for diagnosis and treatment of COVID-19, Version 1.1, March 2020. Available at https://hiph. alexu.edu.eg/images/egyptian_national_guidelines_covid-19.pdf.pdf.pdf.

15. National Health Commission of China. The novel coronavirus pneumonia diagnosis and treatment program, 7th version. China. 2020. http://www. nhc.gov.cn/yzygj/s7653p/202003/46c9294a7dfe4cef80dc7f5912eb1989. shtml. Accessed 04 Apr.

16. Li X, Wang L, Yan S, Yang F, Xiang L, Zhu J et al (2020) Clinical characteristics of 25 death cases with COVID-19: a retrospective review of medical records in a single medical center, Wuhan, China. Int J Infect Dis 94:128-132

17. Zhang X, Tan Y, Ling Y, Lu G, Liu F, Yi Z et al (2020) Viral and host factors related to the clinical outcome of COVID-19. Nature. 583(7816):437-440

18. Du RH, Liang LR, Yang CQ, Wang W, Cao TZ, Li M et al (2020) Predictors of mortality for patients with COVID-19 pneumonia caused by SARS-CoV-2: a prospective cohort study. Eur Respir J 55(5):2000524

19. He F, Luo Q, Lei M, Fan L, Shao X, Huang G et al (2020) Risk factors for severe cases of COVID-19: a retrospective cohort study. Aging (Albany NY) 12(15):15730

20. Yang J, Zheng Y, Gou X, Pu K, Chen Z, Guo Q et al (2020) Prevalence of comorbidities and its effects in coronavirus disease 2019 patient: a systematic review and meta-analysis. Int J Infect Dis 94:91-95

21. Huang R, Zhu L, Xue L, Liu L, Yan X, Wang J et al (2020) Clinical findings of patients with coronavirus disease 2019 in Jiangsu Province, China: a retrospective, multi-center study. PLoS Negl Trop Dis 14(5):e0008280

22. Wang D, Hu B, Hu C, Zhu F, Liu X, Zhang J et al (2020) Clinical characteristics of 138 hospitalized patients with 2019 novel coronavirus-infected pneumonia in Wuhan, China. JAMA 323:1061-1069

23. Debuc B, Smadja DM (2020) Is COVID-19 a new hematologic disease? Stem Cell Rev Rep 12:1

24. Li K, Wu J, Wu F, Guo D, Chen L, Fang Z et al (2020) The clinical and chest CT features associated with severe and critical COVID-19 pneumonia. Investig Radiol 55(6):327-331

25. Xu Z, Shi L, Wang Y, Zhang J, Huang L, Zhang C et al (2020) Pathological findings of COVID-19 associated with acute respiratory distress syndrome. Lancet Respir Med 8(4):420-422

26. McRae MP, Simmons GW, Christodoulides NJ, Lu Z, Kang SK, Fenyo D et al (2020) Clinical decision support tool and rapid point-of-care platform for determining disease severity in patients with COVID-19. Lab Chip 20(12):2075-2085

27. Salamanna F, Maglio M, Landini MP, Fini M (2020) Platelet functions and activities as potential hematologic parameters related to coronavirus disease 2019 (Covid-19). Platelets. 31(5):627-632

28. Frater JL, Zini G, d'Onofrio G, Rogers HJ (2020) COVID-19 and the clinical hematology laboratory. Int J Lab Hematol 42(Suppl 1):11-18
29. Jia Z, Yan L, Ren Z, Wu L, Wang J, Guo J et al (2019) Delicate structural coordination of the severe acute respiratory syndrome coronavirus Nsp13 upon ATP hydrolysis. Nucleic Acids Res 47(12):6538-6550

30. Ruscitti P, Cipriani P, Di Benedetto P, Liakouli V, Berardicurti O, Carubbi F et al (2018) H-ferritin and proinflammatory cytokines are increased in the bone marrow of patients affected by macrophage activation syndrome. Clin Exp Immunol 191(2):220-228

31. Ruddell RG, Hoang-Le D, Barwood JM, Rutherford PS, Piva TJ, Watters DJ et al (2009) Ferritin functions as a proinflammatory cytokine via ironindependent protein kinase C zeta/nuclear factor kappaB-regulated signaling in rat hepatic stellate cells. Hepatology. 49(3):887-900

32. Liu W, Zhang S, Nekhai S, Liu S (2020) Depriving iron supply to the virus represents a promising adjuvant therapeutic against viral survival. Curr Clin Microbiol Rep 20:1-7

33. Kappert K, Jahić A, Tauber R (2020) Assessment of serum ferritin as a biomarker in COVID-19: bystander or participant? Insights by comparison with other infectious and non-infectious diseases. Biomarkers. 23:1-36. https://doi.org/10.1080/1354750X.2020.1797880 Epub ahead of print. PMID: 32700561

34. Velavan TP, Meyer CG (2020) Mild versus severe COVID-19: laboratory markers. Int J Infect Dis 95:304-307

35. Mehta P, McAuley DF, Brown M, Sanchez E, Tattersall RS, Manson JJ et al (2020) COVID-19: consider cytokine storm syndromes and immunosuppression. Lancet. 395(10229):1033-1034

36. Yolcu S, Beceren GN, Tomruk Ö, Doguç DK, Balbaloglu O (2014) Can mean platelet volume levels of trauma patients predict severity of trauma? Platelets 25(4):279-84.

37. Lancé MD, Sloep M, Henskens YM, Marcus MA (2012) Mean platelet volume as a diagnostic marker for cardiovascular disease: drawbacks of preanalytical conditions and measuring techniques. Clin Appl Thromb Hemost 18(6):561-568

38. Pulavendran S, Rudd JM, Maram P, Thomas PG, Akhilesh R, Malayer JR et al (2019) Combination therapy targeting platelet activation and virus replication protects mice against lethal influenza pneumonia. Am J Respir Cell Mol Biol 61 (6):689-701

39. Lê VB, Schneider JG, Boergeling Y, Berri F, Ducatez M, Guerin JL et al (2015) Platelet activation and aggregation promote lung inflammation and influenza virus pathogenesis. Am J Respir Crit Care Med 191(7):804-819

40. Sezgi C, Taylan M, Kaya H, Selimoglu Sen H, Abakay O, Demir M et al (2015) Alterations in platelet count and mean platelet volume as predictors of patient outcome in the respiratory intensive care unit. Clin Respir J 9(4):403-408

41. Aktaş A, Sener K, Yılmaz N, Tunç M, Yolcu S (2020) Is mean platelet volume useful for predicting the prognosis of COVID-19 diagnosed patients? IJRSMHS 5(7):8-11

42. Zhong Q, Peng J (2020) Mean platelet volume/platelet count ratio predicts severe pneumonia of COVID-19. J Clin Lab Anal 31:e23607. https:// doi.org/10.1002/jcla.23607 Epub ahead of print. PMID: 33128497

\section{Publisher's Note}

Springer Nature remains neutral with regard to jurisdictional claims in published maps and institutional affiliations.

\section{Submit your manuscript to a SpringerOpen ${ }^{\circ}$ journal and benefit from:}

- Convenient online submission

- Rigorous peer review

- Open access: articles freely available online

- High visibility within the field

- Retaining the copyright to your article

Submit your next manuscript at $\boldsymbol{\nabla}$ springeropen.com 